This document is the accepted manuscript version of a published work that appeared in final form in the British Journal of Midwifery, copyright (C) MA Healthcare, after peer review and technical editing by the publisher. To access the final edited and published work see http://www.magonlinelibrary.com/doi/10.12968/bjom.2015.23.8.594

\title{
What do service users want and who cares?
}

\section{Abstract}

The NHS Constitution (Department of Health (DH), 2013) sets out the principles and values of the NHS in England: in essence, care should be planned and provided in partnership with service users and their families and this patientfocused approach should be of a consistently high quality with respect, dignity, compassion and care as core values.

The newly updated Code (NMC, 2015) concurs with this philosophy by stating the interests of service users must come first by ensuring their privacy, dignity and confidentiality are preserved and their needs are recognised, assessed and met. Furthermore, the introduction of Revalidation (NMC, 2015) to replace the Post-registration education and practice (Prep) standards (NMC, 2011) includes the requirement for midwives to demonstrate to the NMC on a regular basis that they continue to remain fit to practise, which will in part be evidenced by written reflective accounts, based on the requirements of the Code, using feedback from service users, patients, relatives, colleagues and others (NMC, 2015).

This article will provide a definition of a service user in the context of maternity services and outline current policy and professional body requirements in relation to service user involvement in care. It will then look at the literature with regards service user expectations of 'a good midwife' and the Friends and Family Test (FFT) (NHS England, 2015) to consider the relationship between policy, practice and service user experiences and expectations.

Keywords: service user; revalidation; partnership working; service user involvement; Friends and Family Test

\section{Introduction}

The word midwife originates from Middle English: probably from the obsolete preposition mid 'with' + wife (in the archaic sense 'woman') (Oxford Dictionaries, 
2015). The current International Confederation of Midwives (ICM), 2011: Scope of Practice) definition concurs, stating that the midwife 'works in partnership with women'. So the idea of the midwife working with women is not new; however the expectation of women being equal partners in the decision-making about their care has become a priority in government policy and professional regulation.

\section{What is a Service User?}

There is no one definition of a healthcare service user. The Health Professions Council's (HPC) definition is:

those who typically use or are affected by the services of registrants once they qualify from programmes and become registered (eg patients, clients, carers, organisational clients, colleagues etc.)

(Chambers and Hickey, 2012:5)

From the service user's perspective the Shaping our Lives (2015) National User Network views the term as active, positive and meaning more than one thing including the entitlement to receive welfare services and the belief that the shared experience of using services empowers the individual to have a voice and some control over the kind of services they want. Maternity services differ from other healthcare services in that the majority of women and babies receiving care are not ill, but fit and healthy. The definition of a service user in this context is more time specific, namely those women who access maternity services from 'the period from conception to shortly after birth' (Blunt, 2014:4), after which time the baby is also a service user.

\section{What is current policy?}

The concept of the 'patient' no longer being a passive recipient of care is captured in current policy with the phrase 'no decision about me, without me' (Department of Health (DH), 2010:3) and is embedded within maternity services in response to a succession of policy documents starting with Changing Childbirth (Expert Maternity Group, 1993) which identified choice, control and continuity of care as the most important elements of maternity care. This landmark report has been followed by a succession of policy documents outlining how services should be high quality, individualised and woman-centred ( $\mathrm{DH}$, 
2004; DH/Partnerships for Children, Families and Maternity, 2007). Most recently, the key messages from Midwifery 2020: delivering expectations (Chief Nursing Officers of England, Northern Ireland, Scotland and Wales, 2010) are that women's needs must be met by ensuring they are supported to have a positive and life enhancing transition to parenthood. From the service user's perspective, The Patient Experience Network for NHS England's report on how to improve maternity service users' experiences (Blunt, 2014) also recommended greater involvement and a louder voice for service users.

\section{What is the NMC's standpoint?}

The Nursing and Midwifery Council (NMC) sets standards in relation to the quality of undergraduate education and continuing professional development (CPD); professional behaviour and practice to ensure the public consistently receive high quality, evidence-based healthcare. The newly updated Code (NMC, 2015) clearly states the interests of service users must come first by ensuring their privacy, dignity and confidentiality are preserved and their needs are recognised, assessed and met. Furthermore, the introduction of Revalidation (NMC, 2015) to replace the Post-registration education and practice (Prep) standards (NMC, 2011) includes the requirement for midwives to demonstrate to the NMC on a regular basis that they continue to remain fit to practise. This will in part be evidenced by 5 written reflective accounts over a 3 year period, based on the requirements of the Code, using feedback from service users, patients, relatives, colleagues and others (NMC, 2015).

\section{What do women want from maternity services?}

A literature review into women's definitions of 'a good midwife' identified the possession of theoretical knowledge and clinical competency as key attributes; however good interpersonal skills and moral/ethical values are seen as equally as important for a service where women feel supported, empowered and informed (Borrelli, 2014). Nicholls et al. (2011) identified the three most important qualities of a good midwife to be the provision of individualised care; good communication skills and being life-long learners. In terms of policy, the Health Care Commission's survey in 2007 found that women identify communication, support, being involved in their care and being treated with respect, dignity and kindness as key to a positive childbirth experience. 


\section{How is service user satisfaction measured?}

The Friends and Family Test (FFT) was launched in April 2013 and implemented in maternity services in England from October 2013 with the aim of providing service users with a voice regarding the quality of the care they have received. Service users are asked the question 'Would you recommend this service to friends and family' with a descriptive six-point response scale from 'extremely likely' to 'extremely unlikely'. This trigger question is the followed by an open ended question such as 'Why have you chosen this response?' to elicit more indepth, qualitative feedback. By asking people's opinion on the services they have received it is hoped that the quality of care, both good and poor, will be highlighted in order to improve services to ensure service user expectations are met (NHS England, 2015). In maternity services, women in England are asked about their opinion of the care they have received at three points: in the antenatal period (at 36 week antenatal appointment); at birth or on the postnatal ward (at discharge or following a home birth; in the postnatal period in the community (at discharge from the community midwife). The results are then published on the NHS Choices website thereby providing women with the opportunity to make choices regarding their pregnancy, informed by previous service users' experiences.

\section{What does this mean for midwives?}

Policy and professional regulation dictate that midwives should work in partnership with the women in their care to ensure the service they receive is of the highest quality in the ante, intra and postnatal periods. The service user has been given the opportunity to comment on this care through policy in the form of the Friends and Family Test (FFT) and through professional regulation with the requirement for midwives to write reflective accounts, using service user feedback, to evidence how they are meeting the requirements of the Code (NMC, 2015). The question is can these political and professional measures ensure all women are being cared for by 'a good midwife'? Can the complex 'soft skills' identified as key attributes by women themselves (Borrelli, 2014; Nicholls et al., 2011; Health Care Commission, 2006) be measured by a six-point scale? 


\section{References}

Blunt L (2014) Improving Service User Experience in Maternity Services. A report prepared by The Patient Experience Network. The Patient Experience Network [online]. Available from:

http://patientexperiencenetwork.org/Resource/ImprovingPatientExperienceinMat ernityServicesfinal.pdf. [Accessed 01.07.15]

Borrelli S (2014) What is a good midwife? Insights from the literature.

Midwifery 30 3-10

Chambers M, Hickey G (2012) Service User Involvement in the design and delivery of education and training programmes leading to registration with the Health Professions Council. London: Kingston University

Chief Nursing Officers of England, Northern Ireland, Scotland and Wales (2010) Midwifery 2020: delivering expectations. Cambridge: Midwifery 2020 Programme

Department of Health (DH) (2010) Equity and excellence: Liberating the NHS. Department of Health. London: Crown Copyright

Department of Health (DH) (2013) The NHS Constitution: the NHS belongs to us all. London: Crown Copyright

Department of Health/Partnerships for Children, Families and Maternity (2007) Maternity Matters: choice, access and continuity of care in a safe service. London: DH Publications

Department of Health (DH) (2004) Maternity Standard, National Service Framework for Children, Young People and Maternity Services. London: DH Publications

Expert Maternity Group (1993) Changing Childbirth. Part 1: Report of the Expert Maternity Group. London: Department of Health 
Health Care Commission (2007) Women's Experiences of Maternity Care in the NHS in England: Key findings from a survey of NHS Trusts carried out in 2007. London: Commission for Healthcare Audit and Inspection

International Confederation of Midwives (ICM) (2011) ICM International

Definition of the Midwife. International Confederation of Midwives [online].

Available from:

http://www.internationalmidwives.org/assets/uploads/documents/Definition\%20 of\%20the\%20Midwife\%20-\%202011.pdf. [Accessed 09.04.15]

Nicholls L, Skirton H, Webb C (2011) Establishing perceptions of a good midwife: a Delphi Study. British Journal of Midwifery 19 (4) 230-236

NHS England (2015) Introduction to the Friends and Family Test. NHS England [online]. Available from: http://www.england.nhs.uk/ourwork/pe/fft/ [Accessed 13.07.15]

Nursing and Midwifery Council (NMC) (2015) The Code: professional standards of practice and behaviour for nurses and midwives. London: NMC

Nursing and Midwifery Council (NMC) (2011) The Prep Handbook. NMC [Online]. Available from: http://www.nmc-uk.org/Documents/Standards/NMC Prephandbook 2011.pdf. [Accessed 27.02.2015]

Oxford Dictionary (2015) Definition of midwife. Oxford Dictionary [online]. Available from: http://www.oxforddictionaries.com/definition/english/midwife. [Accessed 02.07.15]

Shaping Our Lives (2015) Definitions. Shaping Our Lives [online]. Available from: http://www.shapingourlives.org.uk/definitions.html. [Accessed 13.04.15] 